\title{
Level and Correlates of Unintended Pregnancy among Currently Pregnant Young Women in India
}

\author{
Rajesh Raushan $^{1}$ and Mukesh Ravi Raushan ${ }^{2}$
}

This study examined the level of unintended pregnancy among young Indian women and their co-variate using demographic and health survey data for India collected in 2005-2006 i.e, NFHS-3. The respondents were married young women aged between 15-24 years $(N=19,724)$ who answered questions regarding their status pregnancy. Bivariate analysis was done using chi square test for significance. Factors and correlates were modelled using binary logit regression at 5 percent significance level. 17 percent young women were found currently pregnant and 22 percent (4,046 women) were conceived unintendedly. The number of surviving children, fertility preference, and spousal desire for children, elevates unintended pregnancy. Sexual violence increases the risk and burden of unintended pregnancy $(p<0.05)$ among young women in the country. The study concludes that non-socioeconomic factors particularly sexual violence contributes to unintended pregnancy in India, requiring strong intervention and community participation to advance women empowerment, age at marriage and stop threat of violence to accelerate the goal of sustainable development goals.

Keywords: India, pregnant, sexual violence, unintended, young.

${ }^{1}$ Indian Institute of Dalit Studies (IIDS), New Delhi, India. Email: rajesh.rajiips@gmail.com, rajeshraushan@dalitstudies.org.in

${ }^{2}$ International Institute for Population Sciences (IIPS), Mumbai, India 


\section{Introduction}

Unintended pregnancy is a major concern in India where there is a high fertility rate (IIPS \& Macro, 2007). Studies have delineated a link between fertility transition and unintended pregnancy in developing countries, indicating a rise in unwanted pregnancies during fertility transition, which continues to remain relatively high until the end of the transition period (Bankole \& Westoff, 1995; Bongaarts, 2002). Globally, the share of mistimed and unwanted pregnancies has increased in recent decades due to changing fertility practices and behavior within and between countries. The global estimate of unintended pregnancies done by Sedgh, Singh and Hussain (2014) indicated around 213 million pregnancies happened worldwide; of which around 89 percent (around 190 million) was in developing countries. Interestingly, more than half (around 56 percent) of total pregnancies were in Asia. The study also delineated that of the total number of pregnancies, around 85 million (40 percent) were unintended. Within Asia, a total of 38 percent pregnancies were found to be unintended (out of 119.7 million pregnancies) and of which 36 percent (56.5 million pregnancies- highest among four Asian regions) were in South Central Asia.

Evidences in India have not clearly shown the causal linkages of unintended pregnancy. To elude and prevent unintended pregnancies is remained an integral component of United Nations' Millennium Development Goals (MDGs) under the goal for improving maternal health globally (United Nations [UN], 2009) and now as a component for Sustainable Development Goals (SDGs). Hence, this study will examine the level of unintended pregnancy among young women in India and their regional variation as well as delineate the correlates of unintended pregnancies.

\section{Unintended Pregnancy and Pathways}

Unintended pregnancy denotes pregnancies which either unwanted (occurred when no children or no more children were desired) or mistimed (occurred earlier than desired) (Santelli et al., 2003). Unintended pregnancy reflects the utilization of fertility control measures nested within socio-economic and cultural contexts (Moos, Bartholomew, \& Lohr, 2003). Further, unintended pregnancy encompasses affective, cognitive, cultural and contextual dimensions (Santelli et al., 2003) along with a woman relationship with their partner. Further, pregnancy coercion and contraception sabotage may also increase the chance of unintended pregnancies. 
In a society where women are not capable of making decisions independently regarding their fertility behavior (Jejeebhoy, 1995; Kishor, 2000; Schuler, Hashemi, \& Riley, 1997) and the discontinuation or failure of contraception increased the risk to become pregnant. Notably, low contraceptive prevalence among young couples (IIPS \& Macro, 2007) is common in India. Early age at marriage and poor socioeconomic development followed by low level of autonomy among young Indian women increases the chance of unintended pregnancy (Stephenson et al., 2008; Silverman \& Raj, 2014). The younger a woman at the time of marriage, increases the chances of first sex being non-consensual or forced (Watts \& Zimmerman, 2002; Jejeebhoy \& Bott, 2003). World Health Organization estimated that prevalence of violence against women remained higher for young women indicating the onset of violence early in the marriage (WHO, 2013). National data for India reveals that the mean age of the first experience of intimate partner violence is 20.68 years and almost 86 percent of married women experienced their first act of violence before they reached age of 24 . The mismatch on fertility preference among couples (Tilahun, Coene, Temmerman, \& Degomme, 2014) and violence experienced by a woman led to high proportion of unintended pregnancies (Cripe, Sanchez, Perales, Lam, Garcia \& Williams, 2008).

Consequently, women with unintended pregnancy are at risk of complicated pregnancy outcomes and poor physical and psychological health (Kroelinger \& Oths, 2000). Studies have found linkages between unintended pregnancies and an array of negative health, economic, social, and psychological outcomes for women and children (Marston \& Cleland, 2003; Hardee, Eggleston, Wong, \& Hull, 2004; Gipson, Koenig, \& Hindin, 2008).

\section{Method and Materials}

\section{Data Source}

Third wave of National Family Health Survey (NFHS-3) data were collected in 2005-2006 and were used in this study. National family health survey (NFHS) is a national representative cross-sectional household survey data of women in the reproductive age group of 15-49 years, selected through multi-stage sampling approach. It provides reliable information on fertility behavior \& fertility intention, maternal and child health \& healthcare other than domestic violence and women empowerment (IIPS \& Macro, 2007). It also provides information on socio- 
economic and religious aspects of selected women. NFHS-3 data was collected from 124,385 women of $15-49$ years spread over all 28 states and NCT of Delhi, at the time. Among them 93,724 women who were ever married.

\section{Selection of Study Population}

The study was based on 19,724 ever married young women aged 15-24 years who had reported their pregnancy status at the time of survey in 2005-2006. Among the total surveyed women in 15-49 years, 38 percent ( 46,762 women) were found in this 15-24 years age group and it was 21 percent of total married women in 15-49 years married women. Second, around 60 percent of women in 15-24 years found married before the legal age of 18 ( 81 percent among 15-19 years and 52 percent among 20-24 years women) resulting in early pregnancies (IIPS \& Macro, 2007). Third, selecting pregnant women having reason that pregnancy intention may be clearly captured during the gestation period as many times unwanted pregnancy terminates into abortion or post-delivery intention may be changed for the said pregnancy (Bankhole \& Westoff, 1998). Of the 19,724 ever married women (Weighted $\mathrm{N}=24,003$ women); 3,433 (Weighted $\mathrm{N}=4,060$ women) were found pregnant, and served as the sample size for this study.

\section{Selection of Variables}

\section{Computation of Unintended Pregnancy}

The first question asked to ever married women was "Are you pregnant now?" If affirmative it is followed by the question "At the time when she became pregnant, did she wanted to conceive at the time or later or not at all?" Women who reported they wanted to wait until later, or did not want to conceive at all can be understood as unintended pregnancy. Here, the dependent variable was considered on pregnancy intention, measured on unintended pregnancy (if pregnant women reported for wanted to wait and/or did not want to conceive at all) as ' 1 ', otherwise ' 0 '.

\section{Independent Variables}

The independent variables are socio-economic characteristics, demographic attributes, fertility preference, and knowledge of ovulatory cycle, contraception use and experience of violence. A second set of independent variables included geographical location, socio-economic and cultural characteristics. Other than these, 
states have been identified using criteria followed in NFHS-3 (IIPS \& Macro, 2007). In defining socio-economic characteristics, level of respondent education ( $\mathrm{No} /$ Primary/Secondary/Higher), religion (Hindu/Muslim/Rest) and economic status were considered. For economic status, two types of variables (household economic status and work status of women) were included and their status measured using wealth index as a proxy. The poor were ones who belonged to first and second quintile of wealth index. The women who fall into fourth and fifth quintile of wealth index were considered rich and the women fall in between these two were considered as middle economic status. For women work status, women who were employed in the last 12 month were considered.

Demographic characteristics included women age (15-19 years/20-24 years), number of male and female children (None/One/Two \& above) were considered. Son (male children) and daughter (female children) were considered separately to observe variation in unintended pregnancy with son preference. Further; fertility preference on women choice for additional children was categorized into wanted another, undecided and no more; husband desire on number of children categorized as both wanted equally, husband wanted more and husband wanted less. Knowledge of ovulatory cycle (Before/During/After, Middle, Any time/Don't Know) was also why ovulation is predominant factor in conception.

Use of contraception and experience of any type of violence in last 12 months were included in the study for the reason that absence of contraception and experience of violence may propagate the risk of unintended pregnancy, as reported in previous studies (Campbell, 2002; Black, Gupta, Rassi \& Kubba, 2010). Contraceptive use was categorized into no use, use of traditional method and modern methods. A set of variables pertaining to violence had been examined in various counties for adverse demographic outcomes was needed for inclusion under the study in Indian context (Watts \& Zimmerman, 2002; Jejeebhoy \& Bott, 2003; Begum et al., 2010; WHO, 2013; Silverman \& Raj, 2014). Experience of different type of violence in last 12 months includes physical, emotional and sexual violence. Severe forms of physical violence included attempts to murder. Emotional violence included humiliation, threats to hurt, and insulting. Sexual violence also included forced sexual intercourse or any other sexual act against respondent's will (No/Yes).

\section{Statistical Techniques}

Bivariate analysis using chi square test of significance was used to understand variation in unintended pregnancies at regional level, association with contraception 
use and violence. Multivariate analysis using binary logit regression model was applied to delineate the co-factors response into conceive unintendedly among young women and it was explained through odds ratio $(\operatorname{Exp} \beta)$. Co-variate/co-relates had been regressed on three models to examine the factors responsible for unintended pregnancy among 15-24 year old women. The first model included socio-economic characteristics, the second model included demographic and fertility intention other than socio economic characteristics; and the third model included the use of contraception and violence variables other than variables of second model. All the three models were controlled on region. Model fitness is represented with -2 $\log$ likelihood values and $\mathrm{R}$ square statistics. Test of significance for each of the model was checked through chi-square value. All the analysis was conducted using SPSS version 20.0.

\section{Results}

\section{Level and regional pattern of unintended pregnancy among young women}

An overview of pregnancy status and intention can be found in Table 1. Overall 6.5 percent $(6,425)$ women in the 15-49 years women were found pregnant at the time of survey in 2005-2006. Whereas around 17 percent women were pregnant in the 15-24 age group. When considering the total number of pregnant women within 15-24 age groups, it was just less than two-third (63 percent) of total pregnant women in 15-49 years age group. The proportion of pregnant women aged 15-19 years and 20-24 years was 20 percent and 16 percent respectively.

Table 1: Pregnancy Status and Intention among Married Women in India

\begin{tabular}{|c|c|c|c|c|}
\hline \multirow{2}{*}{ Pregnancy } & \multicolumn{2}{|c|}{ 15-49 Years } & \multicolumn{2}{|c|}{ 15-24 Years } \\
\hline & $\%$ & Weighted N & $\%$ & Weighted N \\
\hline Yes & $6.5(6,425)$ & 98,923 & $16.9(4,060)$ & 24,003 \\
\hline Intention & & & & \\
\hline Intended & 75.2 & 4,757 & 77.9 & 3,112 \\
\hline Mistimed & 15.3 & 966 & 17.5 & 699 \\
\hline Not wanted at all & 9.5 & 600 & 4.6 & 182 \\
\hline Unintended & 24.8 & 1,566 & 22.1 & 881 \\
\hline $\mathrm{N}$ & 100 & $6,323^{\oplus}$ & 100 & $3,993^{\varrho \varrho}$ \\
\hline
\end{tabular}

@Information for 102 women on pregnancy intention was not available.

@@ Information for 67 women on pregnancy intention was not available. 
Around 22 percent of pregnant women (15-49 years) had reported for conceived unintendedly, 17.5 percent of which were mistimed and the rest 4.6 percent not wanted at all. Importantly, 56 percent of total unintended pregnancy was among women aged 15-24 years. Notably, with increasing reproductive age, the proportion of unintended pregnancy increases. Within that the proportion of mistimed pregnancy decreases with increasing age and not wanted at all pregnancy increases simultaneously (Table A1). Regional pattern of unintended pregnancy (Figure 1) revealed the north-east, east and central region had a high percentage of unintended pregnancy (around 24-25 percent in each of these region) and lowest (16 percent) in western region $(p<0.001)$.

Figure 1: Regional Pattern of Unintended Pregnancy among Young Women in India

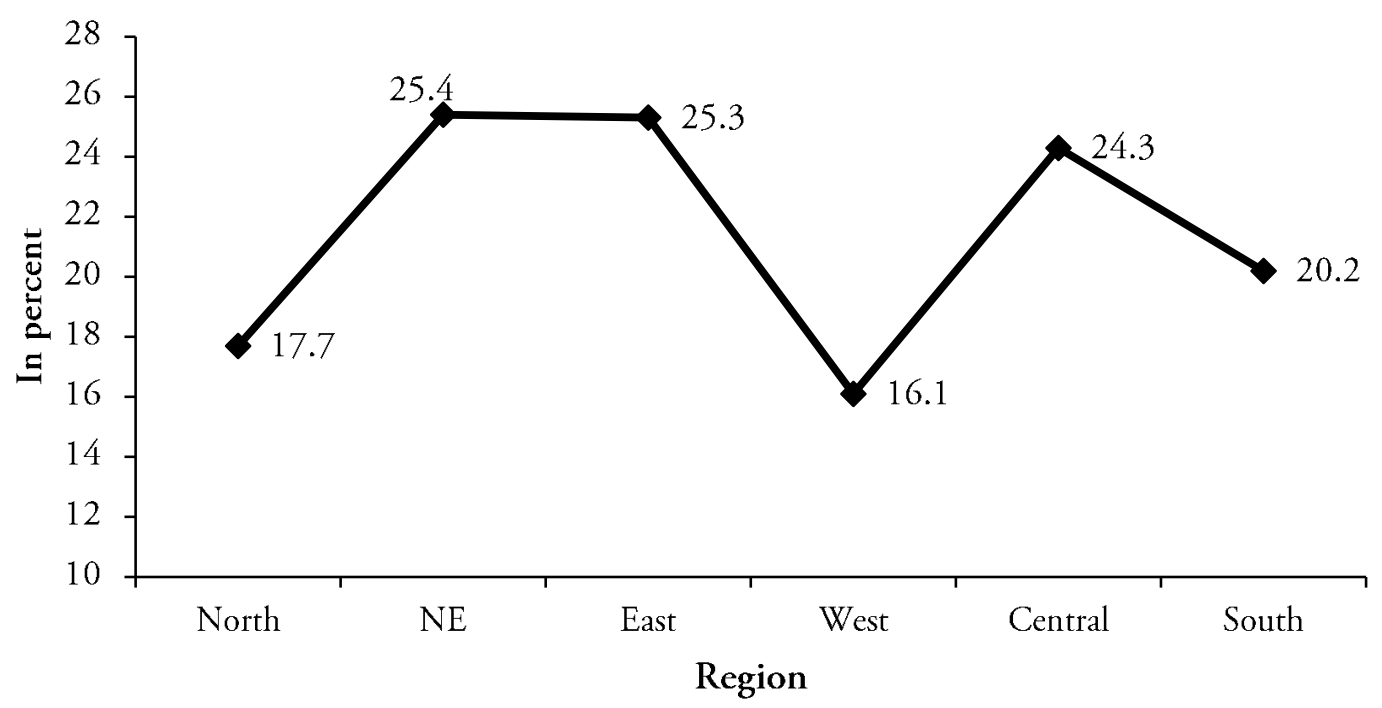

\section{Relationship between Unintended Pregnancy and Knowledge of Ovulation, Contraception Use, Experience of Violence}

The relationship between knowledge of ovulatory cycle, use of family planning methods, experience of violence and magnitude of unintended pregnancy was examined and their statistical significance assessed using chi square test of association. The result can be found in Table 2, and shows knowledge and awareness 
about ovulatory cycle among young women reduced the risk of unintended pregnancies. With regards use of contraception it was found women who used contraception had a high prevalence of unintended pregnancies was high $(p<0.001)$. Violence increased the magnitude of unintended pregnancy among young women and highest among those who had faced sexual violence in last 12 months $(p<0.005)$.

Table 2: Percentage of Young Women Reported Unintended Pregnancy on Various Factors

\begin{tabular}{|c|c|c|c|c|}
\hline Factor & Percent & Number & Chi Value & p-value \\
\hline \multicolumn{5}{|l|}{ Ovulation } \\
\hline Knowledge of ovulatory cycle & & & 2.025 & 0.363 \\
\hline Before/during/after of cycle & 22.9 & 1,140 & & \\
\hline Middle of cycle & 19.8 & 525 & & \\
\hline Any time/don't know & 22.2 & 2,327 & & \\
\hline \multicolumn{5}{|l|}{ Contraception use } \\
\hline Ever use of contraception & & & 56.006 & 0.000 \\
\hline Never used & 19.5 & 3,083 & & \\
\hline Traditional method & 26.4 & 331 & & \\
\hline Modern method & 33.0 & 579 & & \\
\hline \multicolumn{5}{|l|}{ Faced violence in last 12 months } \\
\hline Experience less severe physical violence & & & 14.678 & 0.000 \\
\hline No & 19.8 & 1,854 & & \\
\hline Yes & 26.4 & 852 & & \\
\hline Experience severe physical violence & & & 0.378 & 0.294 \\
\hline No & 21.8 & 2,472 & & \\
\hline Yes & 23.5 & 234 & & \\
\hline Experience emotional violence & & & 3.942 & 0.029 \\
\hline No & 21.2 & 2,325 & & \\
\hline Yes & 25.8 & 380 & & \\
\hline Experience sexual violence & & & 16.588 & 0.000 \\
\hline No & 20.8 & 2,407 & & \\
\hline Yes & 31.1 & 299 & & \\
\hline
\end{tabular}

\section{Correlation of Unintended Pregnancy among Young Women}

The results of logit regression for unintended pregnancy among women aged 15-24 years are provided through odds ratio (Table 4). Three models were run simultaneously. First model controlled on socio-economic characteristic of women. Second model controlled for demographic characteristics and behavior 
of women along with characteristics of first model. Third model controlled on contraception use and experience of different type of violence along with characteristics of model 2.

Model goodness of fit was utilized to examine through $-2 \log$ likelihood value; and significance level was depicted using chi square test (Table 3). Result showed improvement over null model with $-2 \log$ likelihood value significantly different from zero $(3498.34, p<0.001)$ after entering the correlates into the model, although the Negelkerke $\mathrm{R}^{2}$ indicated that the model accounted for only 3 percent of the total variance. The correct prediction rate was 77.6 percent. Model 2 showed the difference of $-2 \log$ likelihood ratio is high (3498.34 - 2886.86=611.48). Model 2 showed improvement in Negelkerke $\mathrm{R}^{2}$, indicating 12.9 percent of the total variance supports. Model 3 results shows a further improvement from model 2 and the difference of $-2 \log$ likelihood ratio increased by 894 points and the total variance explained by the model increased to 14.8 percent.

Table 3: Model Specification on Predicting Risk of Unintended Pregnancy Aged 15-24 Years Women

\begin{tabular}{lcrrrc}
\hline \multicolumn{1}{c}{ Model } & $\begin{array}{c}-2 \text { Log } \\
\text { likelihood }\end{array}$ & $\begin{array}{c}\text { Cox \& Snell } \\
\text { R square }\end{array}$ & $\begin{array}{c}\text { Nagelkereke } \\
\text { R square }\end{array}$ & $\begin{array}{c}\text { Chi Square } \\
\text { value }\end{array}$ & $\begin{array}{c}\text { Significance } \\
\text { level }\end{array}$ \\
\hline Model 1 & $3,498.45$ & 0.020 & 0.030 & 67.019 & $p<0.001$ \\
Model 2 & $2,886.86$ & 0.085 & 0.129 & 261.524 & $p<0.001$ \\
Model 3 & $1,992.82$ & 0.097 & 0.148 & 210.583 & $p<0.001$ \\
\hline
\end{tabular}

The socio-economic, demographic, contraception and experience of violence are presented through odds ratio in Table 4. Of the socio-economic factors, only women's education contributed significantly to unintended pregnancy. The odds of education were almost two times higher for primary and secondary educated women compared to those who had higher education (OR: 2.02, $p<0.01$ for primary and OR: $2.22, p<0.01$ for secondary educated women). However, education became insignificant when the pregnancy intention was controlled for demographic, contraceptive use and experience of violence. However, geographic region had contributed significantly for all the three models, although odds of unintended pregnancies increased when controlled on demographic, contraception and violence factors. 
Table 4: Odds of Unintended Pregnancy among Women Aged 15-24 Years Women in India

\begin{tabular}{|c|c|c|c|c|c|c|}
\hline \multirow{2}{*}{ Factor } & \multicolumn{2}{|c|}{ Model 1} & \multicolumn{2}{|c|}{ Model 2} & \multicolumn{2}{|c|}{ Model 3} \\
\hline & $\operatorname{Exp}(B)$ & $P$ value & $\operatorname{Exp}(B)$ & $P$ value & $\operatorname{Exp}(B)$ & P value \\
\hline \multicolumn{7}{|c|}{ Women education ( $r=$ Higher) } \\
\hline No education & 1.644 & 0.071 & 0.893 & 0.705 & 1.450 & 0.37 \\
\hline Primary & 2.024 & 0.012 & 1.259 & 0.446 & 1.826 & 0.148 \\
\hline Secondary & 2.223 & 0.002 & 1.601 & 0.089 & 2.182 & 0.046 \\
\hline \multicolumn{7}{|l|}{ Economic status ( $r=$ Rich) } \\
\hline Poor & 1.024 & 0.842 & 0.937 & 0.616 & 0.845 & 0.298 \\
\hline Middle & 1.061 & 0.609 & 1.013 & 0.917 & 1.148 & 0.363 \\
\hline \multicolumn{7}{|c|}{ Women work status $(r=N o)$} \\
\hline Yes & 1.025 & 0.823 & 1.029 & 0.817 & 1.009 & 0.951 \\
\hline \multicolumn{7}{|l|}{ Religion ( $r=$ Rest) } \\
\hline Hindu & 1.08 & 0.636 & 1.015 & 0.935 & 1.179 & 0.497 \\
\hline Muslim & 1.301 & 0.147 & 1.192 & 0.396 & 0.740 & 0.04 \\
\hline \multicolumn{7}{|c|}{ Women age ( $r=20-24$ years $)$} \\
\hline $15-19$ years & & & 0.676 & 0.001 & 0.740 & 0.040 \\
\hline \multicolumn{7}{|c|}{ Male children alive ( $r=2 \&$ above) } \\
\hline None & & & 0.234 & 0.000 & 0.318 & 0.000 \\
\hline One & & & 0.455 & 0.000 & 0.578 & 0.027 \\
\hline \multicolumn{7}{|c|}{ Female children alive ( $r=2 \&$ above) } \\
\hline None & & & 0.403 & 0.000 & 0.394 & 0.000 \\
\hline One & & & 0.636 & 0.014 & 0.599 & 0.013 \\
\hline \multicolumn{7}{|c|}{ Spouse preference on number of children ( $r=$ Less) } \\
\hline Both wants same & & & 0.573 & 0.014 & 0.451 & 0.003 \\
\hline Husband want more & & & 0.915 & 0.734 & 0.742 & 0.341 \\
\hline \multicolumn{7}{|c|}{ Women fertility preference ( $r=$ No more) } \\
\hline Wanted another & & & 0.594 & 0.000 & 0.622 & 0.002 \\
\hline Undecided & & & 0.923 & 0.683 & 0.781 & 0.318 \\
\hline \multicolumn{7}{|c|}{ Ever user of contraception ( $r=$ Modern method) } \\
\hline No Use & & & & & 0.736 & 0.033 \\
\hline Traditional method & & & & & 0.496 & 0.003 \\
\hline \multicolumn{7}{|c|}{ Experience less severe violence $(r=\mathrm{No})$} \\
\hline Yes & & & & & 1.024 & 0.864 \\
\hline \multicolumn{7}{|c|}{ Experience sexual violence $\left(r=N_{0}\right)$} \\
\hline Yes & & & & & 1.488 & 0.043 \\
\hline \multicolumn{7}{|l|}{ Region ( $r=$ South) } \\
\hline North & 0.706 & 0.027 & 0.69 & 0.031 & 0.787 & 0.259 \\
\hline North East & 1.415 & 0.028 & 1.454 & 0.031 & 1.578 & 0.033 \\
\hline East & 1.392 & 0.023 & 1.442 & 0.022 & 1.737 & 0.007 \\
\hline West & 0.638 & 0.013 & 0.629 & 0.018 & 0.747 & 0.218 \\
\hline Central & 1.185 & 0.223 & 1.228 & 0.179 & 1.383 & 0.095 \\
\hline Constant & 0.122 & 0.000 & 5.886 & 0.003 & 4.268 & 0.047 \\
\hline
\end{tabular}


Model 2 (Table 4) found women age, number of surviving male and female children, and fertility intention, contributed significantly to unintended pregnancy in India. Like, the odds of having a male child was $0.44(p<0.001)$ compared to women having two or more male children. In case of a female child the odds were $0.599(p<0.05)$. However, having a female child reduces the risk to conceive unintendedly. Women fertility preference showed that women who did not want more children were found at high risk of conceiving unintendedly compared to those who wanted another child (OR: $0.59, p<0.001$ ). Odds of conceiving unintendedly was observed to be less (OR: $0.57, p<0.01)$ when both partners agree on number of children compared to when the male spouse desired fewer children. Model 3 delineates the correlates of unintended pregnancy among women using modern methods of contraception and found them to be greater $(p<0.001)$ than those who did not use contraceptives. Controlling for threat of sexual violence in Model 3 revealed that the women who have experienced sexual violence has 1.48 times higher chance of having unintended pregnancy than who didn't have sexual violence (OR: $1.48, p<0.05$ ). Notably, including contraception use and violence variable in model, women education (Model 3) strengthened and risk of unintended pregnancy increased. However, women education level attenuated and remained insignificant.

\section{Discussion and Conclusion}

The paper examined the level of unintended pregnancy among women in India although the country is moving close to replacement level status. The respondents included in the study were married women who were pregnant at the time when the survey was conducted. This study found that about 17 percent of young women were pregnant in the age group 15-24 years. Among the young pregnant women around 22 percent conceived unintendedly and 17 percent of the pregnancies were mistimed and around 5 percent reported as unwanted. At early age, as the many women would not have been completed their desired family size or wanted additional children might lead them to report the pregnancy as mistimed because they might not be psychologically ready to conceive. It can be very clearly understood from the findings of the other studies that as the number of children among young women increases reporting of unintended pregnancy also increase (Begum, Donta, Nair, \& Prakasam, 2015). A community based cross-sectional household survey was carried out among eligible women for the study during September 2012 to January 2013. A total of 1,137 currently married women aged $18-39$ years with unmet need for family planning and having at least one child were selected using cluster systematic random sampling from two urban slums. Information on socio- 
demographic, reproductive and domestic violence was collected through face-to-face interview using a pretested structured questionnaire after obtaining informed written consent. Bivariate and multivariate analyses were carried out to find the sociodemographic factors associated with ever experienced domestic violence among women. The prevalence of women ever experiencing domestic violence in the community was 21.2 per cent. Women whose husband consumed alcohol [RR: 2.17, (95\% CI: $1.58-2.98)]$.

The result found a significant relationship between unintended pregnancy and the number of surviving children, women fertility preference and spouse's desire for children. The mismatch between a husband and wife's desire on the number of children had elevated significantly the risk among young women to become pregnant. This is consistent with an Indonesian study which revealed that the husband's wish significantly influenced pregnancy (Nur, Peter, \& Iwu, 2009) and a study in Southern Ethiopia which reported that the husband's desire for limiting family size has contributed to unintended pregnancy.

The status of women in the household reveals that those who had experienced a threat of sexual violence experienced unintended pregnancy (Begum et al., 2010; Pallitto, García-Moreno, Jansen, \& Heise, 2013; Shabnam \& Mukherjee, 2013). A study by Raushan and Raushan (2014) found highest magnitude of sexual violence in north-east, eastern and central region of the country and confirms the finding on the highest proportion of unintended pregnancies to be in these regions $(p<0.001)$ clearly support the dominant effect of sexual violence on unintended pregnancy in India. Possibly, the contraception discontinuation may also be one of the outcomes for the same (Stephenson \& Koenig, 2008; Curtis, Evens \& Sambisa, 2011). When including the variable of sexual violence in model, it reduces the risk and probability of other parameters depicts clearly that poor bargaining power of the women and patriarchal influence might have contributed more in this regard (Santhya, Haberland, Ram, Sinha \& Mohanty, 2007; Koenig, Stephenson, Ahmed, Jejeebhoy \& Campbell, 2006). Hence, forced sex or sexual violence is one of the major co-variates of unintended pregnancy in India (Watts \& Zimmerman, 2002; Jejeebhoy \& Bott, 2003; Stephenson \& Koeing, 2008; Cripe et al., 2008; Begum et al., 2010; Silverman \& Raj, 2014).

Overall, this study tried to explain the magnitude and distribution of unintended pregnancies and their correlates among young women in India. The risk of unintended pregnancies was high among the ever user couple as the missing of use of method and poor knowledge of ovulatory cycle might result in untimely 
conception (Begum et al., 2010; Hamdela \& Tilahun, 2012; Raihana, Shaheen \& Shafiqur Rahman, 2012; Shabnam \& Mukharjee, 2013). However, previous study found that in the countries with moderate to high contraceptive prevalence, the majority of unintended pregnancies were the result of either contraceptive discontinuation or contraceptive failure (Black et al., 2010). Possibly, ever user having high expectations about spacing but contraceptive failure led them to report the pregnancies as unintended. The lack of an association between contraceptive knowledge and exposure of birth averting and limiting methods and pregnancy intention delineates that awareness and exposure doesn't always manipulate into correct and effective use of the services (Islam \& Rashid, 2005; Adhikari, Soonthorndhada, \& Prasartkul, 2009). There is the possibility that poor negotiating power of women overpower the husband desire of family size and decision for women life (Dyson \& Moore, 1983). As many study from India have found that poor status of women are major catalyst for adverse demographic and health outcomes (Schuler et al., 1997; Kishor, 2000; Nagarkar \& Mhaskar, 2015) as well as an obstacle in achieving the goal for sustainable development (Hindin, Christiansen \& Ferguson, 2013; Herrmann, 2014).

Major strength of the paper can be understood as it covers various dimensions namely fertility intention, use of family planning services and an array of socio-economic and cultural dimensions other than demographic factors. Emerging studies in south Asian region have found adverse demographic effect of coerced sex (Sedgh, Singh, \& Hussain, 2014) and this paper supports the argument. The study is a step forward in providing some evidences and background on how the strength of childbearing desires and unplanned birth vary by women's age, educational level, number of children a woman already have and her cultural milieu (Sedgh et al., 2014). However, study does not cover potential consequences of unintended pregnancies and is limited to country specific only. The study also having worth that it is free from post-birth rationalization of pregnancy.

This study is limited by the unavailability of recent nationwide data on pregnancy. Defining, measuring and examining causal factors of unintended pregnancies have also presented a major methodological challenge. The study found less effect of socio-economic characteristics excluding women education and majorly by demographic and violence characteristics. The study draw attention to focus on young women to reduce the burden of maternal \& child health (Sedgh, Singh, \& Hussain, 2014) and save the women reproductive rights (Hindin et al., 2013) to accelerate the goal of sustainable development (Herrmann, 2014). 


\section{Acknowledgement}

An earlier version of the paper was presented during international seminar on "Unintended Pregnancy among the Young: Correlates and Consequences" organised by Asian Population Association's scientific group on Pathways to Adulthood in Asia and the Institute for Population and Social Research, Mahidol University, held in Bangkok, Thailand, during December 1-3, 2014. The authors are gratefully acknowledging the comments made by reviewers to improve quality of the paper.

\section{References}

Adhikari, R., Soonthorndhada, K., \& Prasartkul, P. (2009). Correlates of unintended pregnancy among currently pregnant married women in Nepal. BMC International Health and Human Rights, 9(1), 17.

Bankole, A., \& Westoff, C. F. (1995). Childbearing attitudes and intentions. Demographic and Health Surveys, Comparative Studies No. 17. Calverton, Maryland: Macro International.

Begum, S., Donta, B., Nair, S., \& Prakasam, C. P. (2015). Socio-demographic factors associated with domestic violence in urban slums, Mumbai, Maharashtra, India. Indian Journal of Medical Research, 141(June), 783-788. DOI: $10.4103 / 0971-5916.160701$

Begum, S., Dwivedi, S. N., Pandey, A., \& Mittal, S. (2010). Association between domestic violence and unintended pregnancies in India: findings from the National Family Health Survey-2 data.

Black, K. I., Gupta, S., Rassi, A. \& Kubba, A. (2010). Why do women experience untimed

pregnancies? A review of contraceptive failure rates. Best Practice \& Research. Clinical Obstetrics \& Gynaecology, 24(4), 443-455.

Bongaarts, J. (2002). The end of the fertility transition in the developing world. Population Council Policy Research Division Working paper, No. 161. New York: Population Council.

Campbell, A. A., \& Mosher, W. D. (2000). A history of the measurement of unintended pregnancies and births. Maternal and Child Health Journal, 4(3), 163-169.

Campbell, J. C. (2002). Violence against women II. Health consequences of intimate partner violence. Lancet, 359(9314), 1331-1336. 
Cripe, S. M., Sanchez, S. E., Perales, M. T., Lam, N., Garcia, P. \& Williams, M. A. (2008).

Association of intimate partner physical and sexual violence with unintended pregnancy among pregnant women in Peru. International Journal of Gynaecology and Obstetrics, 100(2), 104-108.

Curtis, S., Evens, E. \& Sambisa, W. (2011). Discontinuation and unintended contraceptive an imperfect relationship. International Perspectives, 37(2), 5866.

Dyson, T. \& Moore, M. (1983). On kinship structure, female autonomy and demographic behaviour in India. Population and Development Review, 9(1), 3560.

Gipson, J. D., Koenig, M. A., \& Hindin, M. J. (2008). The effects of unintended pregnancy on infant, child, and parental health: a review of the literature. Studies in Family Planning, 39(1), 18-38.

GoI. (2013). A strategic approach to reproductive, maternal, newborn, child and young health $(R M N C H+A)$ in India. New Delhi: Ministry of Health and Family Welfare.

Hamdela, B., \& Tilahun, T. (2012). Unwanted pregnancy and associated factors among pregnant married women in Hosanna Town, Southern Ethiopia. PLoS One, 7(6), e39074.

Hardee, K., Eggleston, E., Wong, E. L., \& Hull, T. H. (2004). Unintended pregnancy and women's psychological well-being in Indonesia. Journal of Biosocial Science, 36(5), 617-626.

Herrmann, M. (2014). Sustainable development, demography and sexual and reproductive health: inseparable linkages and their policy implications. Reproductive Health Matters, 22(43), 28-42.

Hindin, M. J., Christiansen, C. S. \& Ferguson, B. J. (2013). Setting research priorities for adolescent sexual and reproductive health in low- and middleincome countries. Bulletin of the World Health Organization, 91(1), 10-18.

IIPS \& Macro International (2007). National Family Health Survey (NFHS-3), 2005-2006. Mumbai: IIPS.

Islam, M. M., \& Rashid, M. (2005). Determinants of Unintended Pregnancy among Ever-Married Women in Bangladesh.

Jejeebhoy, S. J. (1995). Women's education, autonomy, and reproductive behaviour: Experience from developing countries. OUP Catalogue.

Jejeebhoy, S. J. \& Bott, S. (2003) Non-consensual sexual experiences of young people: a review of the evidence from developing countries. South and East Asia Regional Working Papers No. 16. Population Council, Regional Office for South and East Asia, New Delhi, India. 
Kishor, S. (2000). Empowerment of women in Egypt and links to the survival and health of their infants.

Klerman, L. V. (2000). The intendedness of pregnancy: a concept in transition. Maternal and Child Health Journal, 4(3), 155-162.

Koenig, M. A., Stephenson, R., Ahmed, S., Jejeebhoy, S. J. \& Campbell, J. (2006). Individual and contextual determinants of domestic violence in North India. American Journal of Public Health, 96(1), 132-138.

Kroelinger, C. D., \& Oths, K. S. (2000). Partner support and pregnancy wantedness. Birth, 27(2), 112-119.

Marston, C., \& Cleland, J. (2003). Do unintended pregnancies carried to term lead to adverse outcomes for mother and child? An assessment in five developing countries. Population Studies, 57(1), 77-93.

Moos, M.-K., Bartholomew, N. E., \& Lohr, K. N. (2003). Counseling in the clinical setting to prevent unintended pregnancy: an evidence-based research agenda. Contraception, 67(2), 115-132.

Moos, M.K., Petersen, R., Meadows, K., Melvin, C. L., \& Spitz, A. M. (1997). Pregnant women's perspectives on intendedness of pregnancy. Women's Health Issues, 7(6), 385-392.

Nagarkar, A., \& Mhaskar, P. (2015). A systematic review on the prevalence and utilization of health care services for reproductive tract infections/sexually transmitted infections: Evidence from India. Indian Journal of Sexually Transmitted Diseases, 36(1), 18-25. DOI: 10.4103/0253-7184.156690

Nur, J., Peter, M., \& Iwu, D. (2009). Determinants of unintended pregnancy among ever-married women in Indonesia: An analysis of the 2007 Indonesia DHS. Australian Demographic and Social Research Institute.

Pallitto, C. C., García-Moreno, C., Jansen, H. A. F. M., \& Heise, L. (2013). Intimate partner violence, abortion, and unintended pregnancy: results from the WHO Multi-Country Study on Women's Health and Domestic Violence. International Journal of Gynecology and Obstetrics, 120(1), 3-9.

Raihana, S., Shaheen, R., \& Shafiqur Rahman, M. (2012). Influence of intimate partners' violence on unintended pregnancy in Bangladesh. International Journal of Psychology and Behavioral Sciences, 2(5), 159-166.

Raushan, M. R., \& Raushan, R. (2014). Sexual vulnerability of ever married women in India: Evidences of non-consensual forced sex from large scale survey. Journal of Population Sciences, 70(2-3), 163-189.

Santelli, J., Rochat, R., Hatfield-Timajchy, K., Gilbert, B.C., Curtis, K., Cebral, R., Hirsch, J. S., Schieve, L. \& Others (2003). The measurement and meaning of unintended pregnancy. Perspective on sexual and reproductive health, 35(2), 94101. 
Santhya, K. G., Haberland, N., Ram, F., Sinha, R. K. \& Mohanty, S. K. (2007). Consent and coercion: examining unwanted sex among married young women in India. International Family Planning Perspectives, 33(3), 124-132.

Schuler, S. R., Hashemi, S. M., \& Riley, A. P. (1997). The influence of women's changing roles and status in Bangladesh's fertility transition: evidence from a study of credit programs and contraceptive use. World Development, 25(4), 563-575.

Sedgh, G., Singh, S., \& Hussain, R. (2014). Intended and unintended pregnancies worldwide in 2012 and recent trends. Studies in Family Planning, 45(3), 301314.

Shabnam, S. \& Mukherjee, A. (2013). Spousal violence and unintended pregnancy in India: evidence from NFHS-3. Indian Journal of Research and Reports in Medical Sciences, 3(3), 1-8.

Silverman, J. G., \& Raj, A. (2014). Intimate partner violence and reproductive coercion: global barriers to women's reproductive control. PLoS Med, 11(9), e1001723.

Stephenson, R. \& Koenig, M. A. (2008). Domestic violence, contraceptive use, and unwanted pregnancy in rural India. Studies in Family Planning, 39(3), 177186.

Tilahun, T., Coene, G., Temmerman, M., \& Degomme, O. (2014). Spousal discordance on fertility preference and its effect on contraceptive practice among married couples in Jimma zone, Ethiopia. Reproductive Health, 11(1), 27.

United Nations. (2009). The millennium development goals report 2009. New York: Department of Economic and Social Affairs Population Division United Nations: United Nations Publications.

Watts, C. \& Zimmerman, C. (2002) Violence against women: global scope and magnitude. The Lancet, 359, 1232-1237.

World Health Organization (2013). Global and regional estimates of violence against women: prevalence and health effects of intimate partner violence and non-partner sexual violence. World Health Organization, Geneva. 


\section{Appendix}

Table A1: Age Pattern of Pregnancy and Pregnancy Intention among Women aged 15-49 Years in India

\begin{tabular}{lrrrrrrrr}
\hline \multirow{2}{*}{$\begin{array}{c}\text { Age } \\
\text { Group }\end{array}$} & Pregnant & \multicolumn{1}{c}{$\%$} & \multicolumn{3}{c}{ Pregnancy Status } & \multicolumn{4}{c}{ Pregnancy Intention } \\
\cline { 3 - 9 } & & & Total & Intended & Mistimed & $\begin{array}{c}\text { Not } \\
\text { Wanted } \\
\text { at all }\end{array}$ & Unintended & Total \\
\hline $15-19$ & 1,359 & 19.9 & 6,842 & 79.1 & 19.4 & 1.5 & 20.9 & 1,335 \\
$20-24$ & 2,701 & 15.7 & 17,161 & 77.4 & 16.6 & 6.1 & 22.6 & 2,658 \\
$25-29$ & 1,548 & 8.1 & 19,221 & 72.7 & 14.0 & 13.3 & 27.3 & 1,522 \\
$30-34$ & 584 & 3.4 & 17,327 & 67.3 & 8.0 & 24.7 & 32.7 & 578 \\
$35+$ & 233 & 0.6 & 38,372 & 65.2 & 3.5 & 31.3 & 34.8 & 230 \\
$15-24$ & 4,060 & 16.9 & 24,003 & 77.9 & 17.5 & 4.6 & 22.1 & 3,993 \\
$25+$ & 2,365 & 3.2 & 74,920 & 70.6 & 11.5 & 17.9 & 29.4 & 2,330 \\
All & $\mathbf{6 , 4 2 5}$ & $\mathbf{6 . 5}$ & $\mathbf{9 8 , 9 2 3}$ & 75.2 & 15.3 & 9.5 & 24.8 & $\mathbf{6 , 3 2 3}$ \\
\hline
\end{tabular}

Note: Information on pregnancy intention is not available for 102 women and 67 women among aged between 15-49 years and 15-24 years respectively. 
Rajesh Raushan \& Mukesh Ravi Raushan 